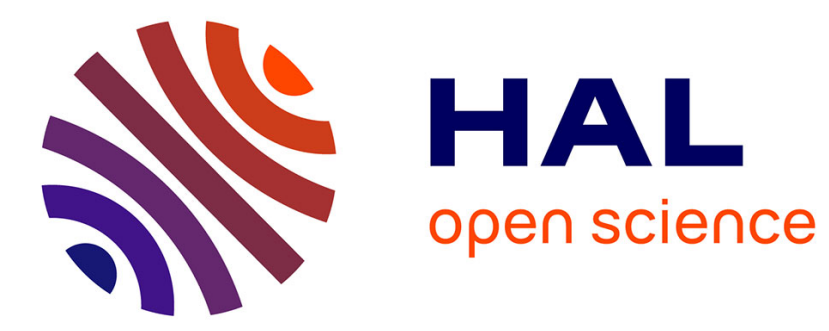

\title{
Validity Domain of the Odunaiya Expression for Computing the Conventional VOR Multipath Error
}

Seif Ben-Hassine, Alexandre Chabory, Christophe Morlaas, Rémi Douvenot

\section{To cite this version:}

Seif Ben-Hassine, Alexandre Chabory, Christophe Morlaas, Rémi Douvenot. Validity Domain of the Odunaiya Expression for Computing the Conventional VOR Multipath Error. EuCAP 2020, 14th European Conference on Antennas and Propagation, Mar 2020, Copenhagen, Denmark. pp.1-5/ ISBN: 978-1-7281-3712-4, 10.23919/EuCAP48036.2020.9135730 . hal-02916307

\section{HAL Id: hal-02916307 https://hal-enac.archives-ouvertes.fr/hal-02916307}

Submitted on 4 Sep 2020

HAL is a multi-disciplinary open access archive for the deposit and dissemination of scientific research documents, whether they are published or not. The documents may come from teaching and research institutions in France or abroad, or from public or private research centers.
L'archive ouverte pluridisciplinaire HAL, est destinée au dépôt et à la diffusion de documents scientifiques de niveau recherche, publiés ou non, émanant des établissements d'enseignement et de recherche français ou étrangers, des laboratoires publics ou privés. 


\title{
Validity Domain of the Odunaiya Expression for Computing the Conventional VOR Multipath Error
}

\author{
Seif Ben-Hassine, Alexandre Chabory, Christophe Morlaas, Rémi Douvenot \\ ENAC, TELECOM-EMA, Université de Toulouse, Toulouse, France, seif.ben-hassine@enac.fr
}

\begin{abstract}
This work presents a method to determine the validity domain of the static Odunaiya expression for computing the VOR multipath error in the presence of wind turbines. The Odunaiya formula is considered valid when it gives the consistent response compared to a dynamic receiver model. This validity domain is then expressed in terms of the Doppler shift of the multipath with respect to the direct path. This leads to a geometric criterion that is illustrated.
\end{abstract}

Index Terms-VOR receiver, Odunaiya, multipath, wind turbines

\section{INTRODUCTION}

The VHF Omnidirectional Range (VOR) systems are essential for air navigation: they give an aircraft its bearing relative to magnetic North. This information can be impaired by surrounding wind turbines that produce multipaths. The on-board VOR receiver processes signals from unwanted directions, which yields bearing error.

To compute the VOR errors, all the models comprise two steps. Firstly, the multipath parameters are obtained by means of a propagation model [3][4][5]. Secondly, the bearing error is calculated from the multipath characteristics using the analytic expression suggested by Odunaiya [1]

In Odunaiya expression, everything is expected static. However, multipaths change quickly in time as the aircraft moves. Thus, we have proposed a digital VOR receiver to reproduce the dynamic response of a realistic VOR receiver [2], taking into account demodulations and filtering. This model has been tested in dynamic scenarios. It has been observed that Odunaiya formula [1] does not always give the consistent response compared to the digital receiver model.

In this article, we propose to determine the validity domain of the static Odunaiya expression for a conventional VOR.

In section II, we present the static Odunaiya expression and the dynamic VOR receiver model used to calculate the bearing error. An example of a simulation where the Odunaiya expression is not valid is presented. In order to explain this phenomenon, we perform in Section III a spectral analysis on the received intermediate signals. In Section IV, we present a criterion that defines the validity domain of the Odunaiya model. It is illustrated by some examples.

\section{VOR RECEIVER MODELS}

\section{A. Times series generator}

The times series generator is applied to obtain time series of the multipath parameters from a realistic aircraft trajectory, i.e. their amplitude $a_{n}$, phase $\theta_{n}$ and azimuth $\varphi_{n}$. The time step between two consecutive epochs is fixed according to a criterion detailed in [2] to accurately model the multipath variations in space.

\section{B. Deterministic propogation model}

At each epoch of the time series, the characteristics of multipaths are computed from an electromagnetic model. The direct signal is calculated using the analytical two-ray method. The multipath signal computation is based on the hybridization of the parabolic equation method (PE) with physical optics (PO) [3]. The model overview is displayed in Figure 1. The

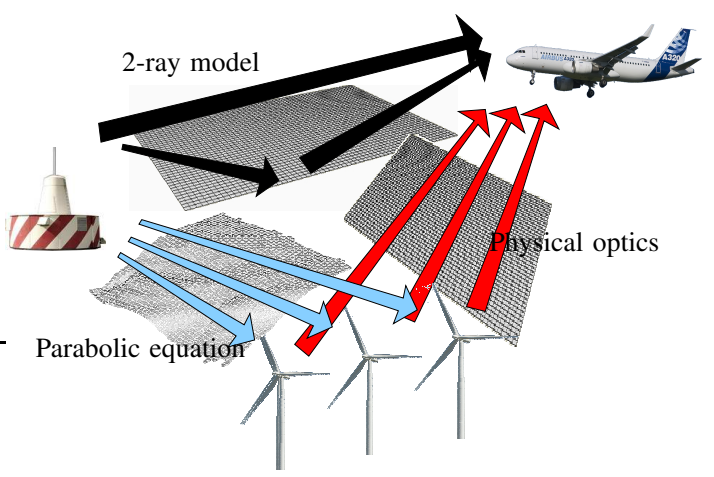

Fig. 1. Overview of the propagation electromagnetic model [3].

multipath characteristics are then inputted into a receiver model to obtain the bearing error.

\section{Static VOR Receiver: Odunaiya model}

For a CVOR, the Odunaiya error is given by [1]

$$
\varepsilon^{c}=\tan ^{-1}\left(\frac{\sum_{n=1}^{N} \frac{a_{n}}{a_{0}} \cos \left(\theta_{n}-\theta_{0}\right) \sin \left(\varphi_{n}-\varphi_{0}\right)}{1+\sum_{n=1}^{N} \frac{a_{n}}{a_{0}} \cos \left(\theta_{n}-\theta_{0}\right) \cos \left(\varphi_{n}-\varphi_{0}\right)}\right)
$$

Note that $a_{0}, \theta_{0}$ and $\varphi_{0}$ corresponds to the direct signal parameters.

This calculation does not take into consideration the dynamic of a mobile aircraft.

\section{Dynamic VOR Receiver}

We have developed a digital VOR receiver to assess the impact of multipath variations in time on the bearing error [2]. Its block diagram is given in Figure 2.

Our model is based on a I/Q signal generator from the multipath parameters. It is able to reproduce a realistic VOR receiver response, taking demodulations and filtering into 


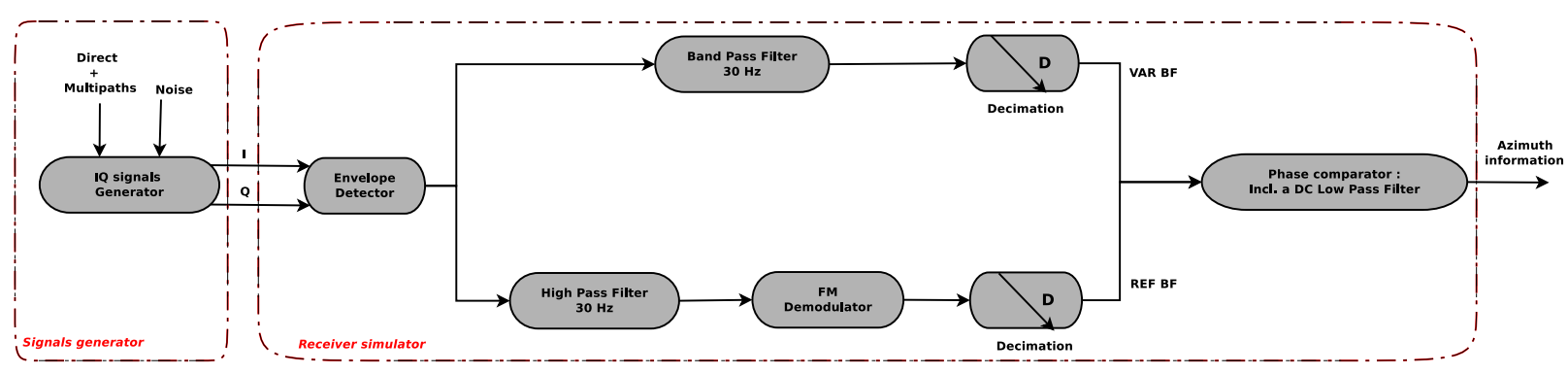

Fig. 2. Block diagram of the VOR receiver.

consideration. For the proposed receiver architecture, a band pass filter is applied to extract the VAR BF signal at $30 \mathrm{~Hz}$ and a low pass filter is performed to recover the DC component that contains the azimuth information in the phase detector. $W_{30}$ and $W_{D C}$ corresponds to the $3 \mathrm{~dB}$ bandwidths of these filters, respectively.

\section{E. Static/Dynamic receivers confrontation}

As shown in Figure 3, we consider a CVOR station with a power of $50 \mathrm{~W}$ operating at a frequency of $113 \mathrm{MHz}$. At $1 \mathrm{~km}$ from the VOR station, there is a generic wind turbine. The aircraft moves along a circular trajectory with a radius of $4.5 \mathrm{~km}$ around the VOR and an altitude of $1 \mathrm{~km}$. The aircraft is motionless for $10 \mathrm{~s}$ to ensure the end of the transient state of the receiver. It starts at low velocity until the end of the trajectory where it reaches a speed of $324 \mathrm{~km} / \mathrm{h} . W_{30}$ and $W_{D C}$ are set to $2 \mathrm{~Hz}$ and $1 \mathrm{~Hz}$, respectively.

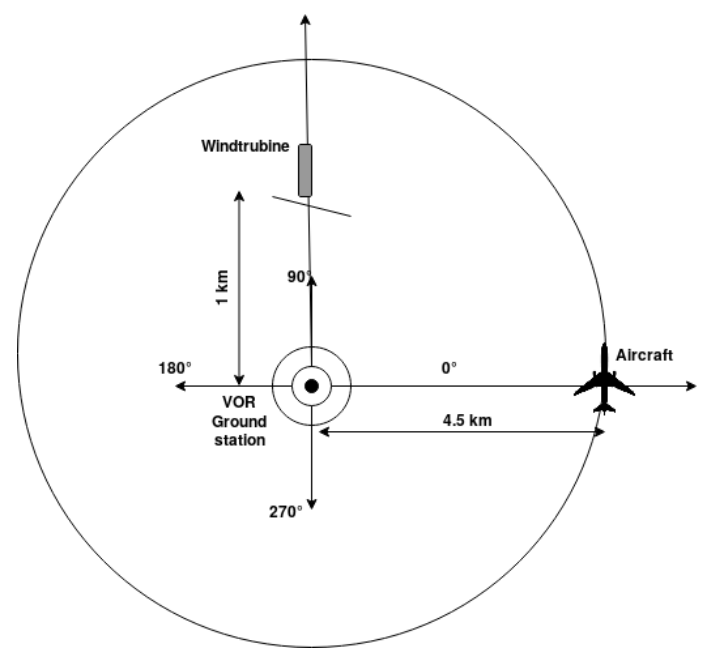

Fig. 3. Configuration.

In Figure 4, we display the instantaneous frequency of the multipath $F_{\text {inst }}$ relatively to the direct path with respect to time. It is calculated from finite differences applied to the phase variation with time. As expected, the Doppler frequency depends on the speed of the aircraft and its position with respect to the VOR station and the wind turbine.

In Figure 5, the VOR errors obtained with the Odunaiya expression and with the VOR receiver model are plotted with

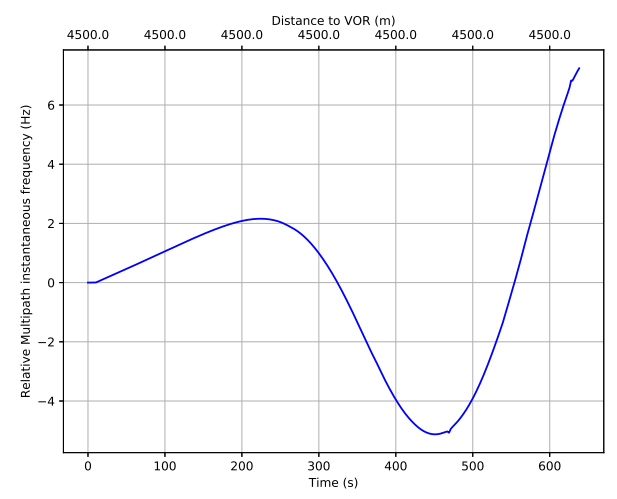

Fig. 4. Relative multipath instantaneous frequency.

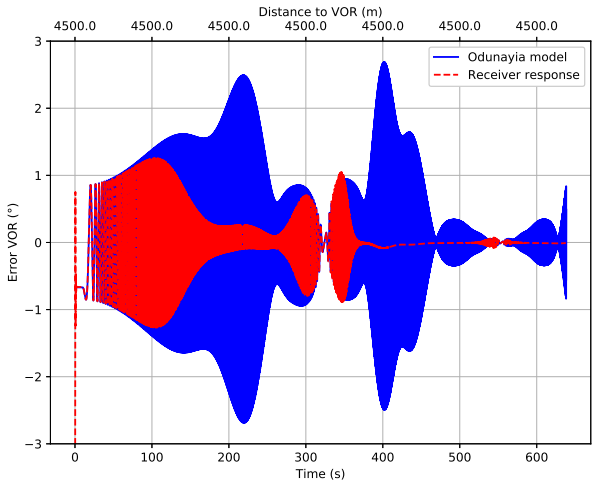

Fig. 5. Receiver response.

respect to time. The receiver response fits with the Odunaiya expression during the first $90 \mathrm{~s}$ when there are no dynamic effects.

As the Doppler effect increases, we can observe significant discrepancies between the static Odunaiya expression and the dynamic VOR receiver model. It is due to the fast variations of multipath.

In section III, we clarify this phenomenon by a spectral analysis for a scenario in the presence of a canonical multipath. 


\section{SPECTRAL ANALYSIS OF THE RECEIVED INTERMEDIATE SIGNALS}

We test here the influence on the bearing error of the bandwidth of receiver filters.

We consider a canonical multipath defined by a parameter with fixed relative amplitude, Doppler shift and azimuth during a simulation time of $50 \mathrm{~s}$. Its relative power is set at $-20 \mathrm{~dB}$. A relative azimuth of $90^{\circ}$ is considered.

\section{A. Case 1 : Doppler shift included in both filter bandwidths}

In this case, the Doppler shift of the multipath is assumed to be included in both $3 \mathrm{~dB}$ bandwidths of filters. Thus, we consider the following parameters : $F_{\text {inst }}=1 \mathrm{~Hz}, W_{30}=6 \mathrm{~Hz}$ , $W_{D C}=3 \mathrm{~Hz}$

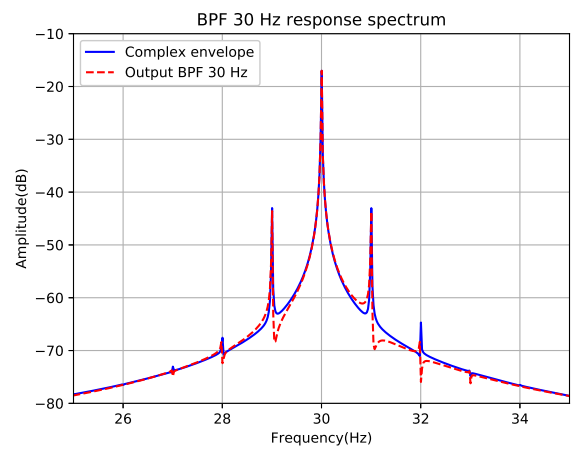

(a) $30 \mathrm{~Hz}$ band pass filter input and output

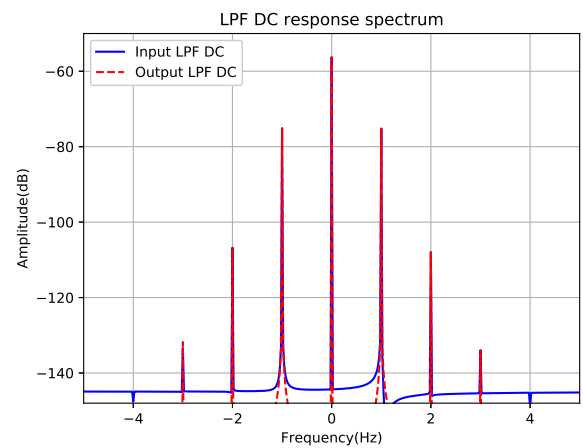

(b) DC low pass filter input and output

Fig. 6. Response of the input and output of receiver filters in case 1.

As shown in Figures $6 a$ and $6 \mathrm{~b}$, we observe that the two filters allow the multipath Doppler shifts at $1 \mathrm{~Hz}$ around the direct signal at $30 \mathrm{~Hz}$ to pass through. Thus, the Odunaiya expression is consistent with the receiver output as shown in Figure 7.

\section{B. Case 2 : Doppler shift is not included in one of both filter bandwidths}

In this case, we consider that the Doppler shift of the multipath is not included in one of both filter bandwidths. First, it is included only in the DC low pass filter. To do this, we set : $F_{\text {inst }}=6 \mathrm{~Hz}, W_{30}=6 \mathrm{~Hz}, W_{D C}=7 \mathrm{~Hz}$. This case is denoted as 2 -a.

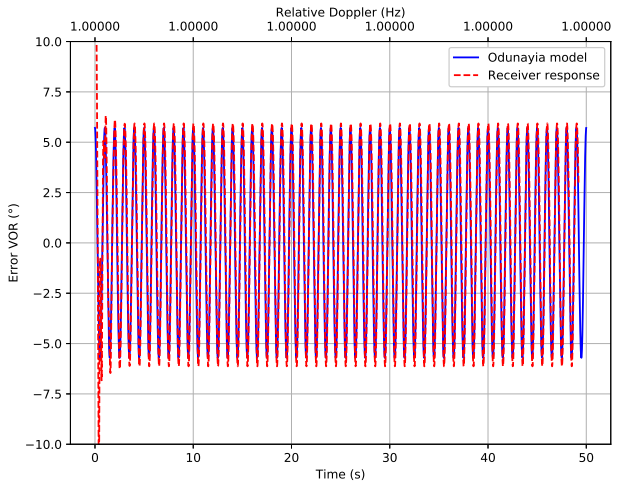

Fig. 7. Receiver response in case 1.

As shown in Figure 8a, the frequency component $(30 \pm$ $\left.F_{\text {inst }}\right)$ is removed by the $30 \mathrm{~Hz}$ band pass filter. Thus, we observe in Figure 9 that the receiver response does not fit with the Odunaiya expression.

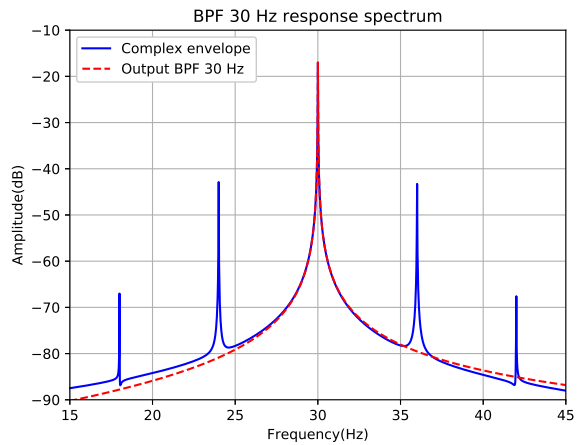

(a) $30 \mathrm{~Hz}$ band pass filter input and output

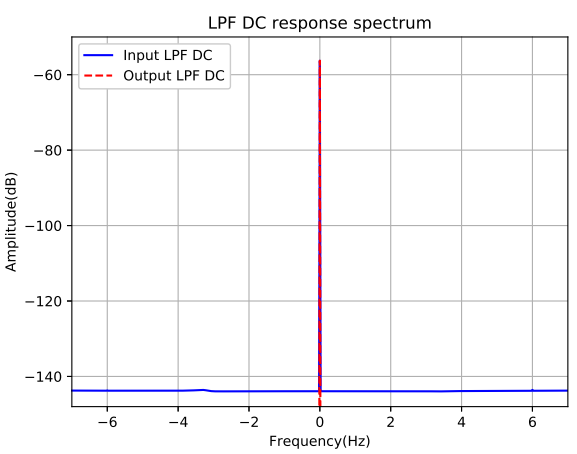

(b) DC low pass filter input and output

Fig. 8. Response of the input and output of receiver filters in case 2-a.

Secondly, we consider that the Doppler shift is included only in the $30 \mathrm{~Hz}$ band pass filter (case 2-b). Thus, we set the following parameters : $F_{\text {inst }}=3 \mathrm{~Hz}, W_{30}=6 \mathrm{~Hz}, W_{D C}=$ $1 \mathrm{~Hz}$.

The $30 \mathrm{~Hz}$ band pass filter allows the frequency component $\left(30 \pm F_{\text {inst }}\right)$ to pass through as shown in Figure 10a. Nevertheless, this component is filtered in the phase comparator. That 


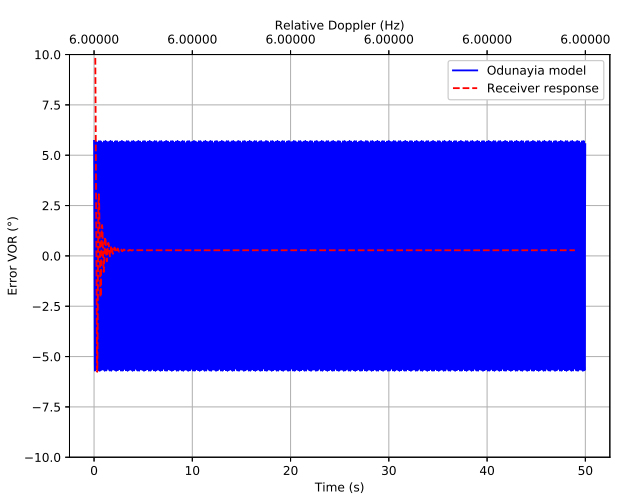

Fig. 9. Receiver response in case 2-a.

explains why in this case the receiver response is different to the one of Odunaiya as shown in Figure 11.

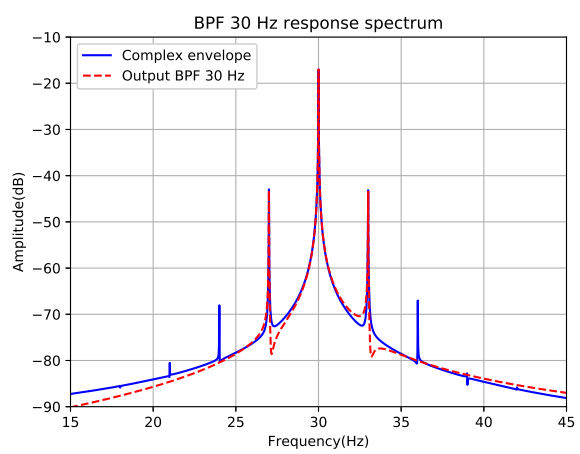

(a) $30 \mathrm{~Hz}$ band pass filter input and output

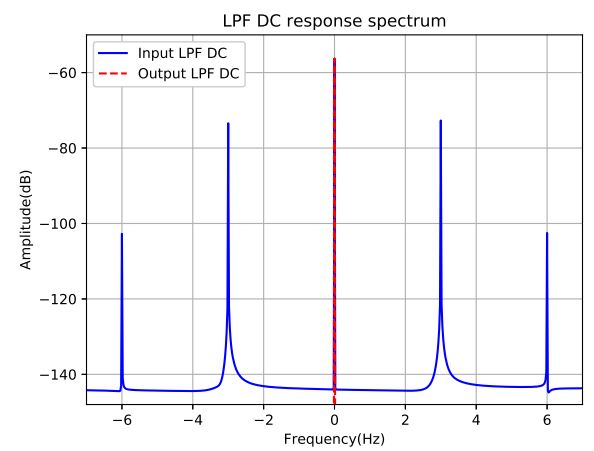

(b) DC low pass filter input and output

Fig. 10. Response of the input and output of receiver filters in case 2-b.

Based on this spectral analysis for a canonical multipath, we observe that the receiver response sensitivity depends on the relative instantaneous frequency of the multipaths and the bandwidth parameters of the receiver filters.

\section{GEOMETRIC CRITERION FOR DYNAMIC SENSITIVITY OF VOR RECEIVER}

In this section, we present a geometric criterion that defines the validity domain of the Odunaiya model. It is illustrated by

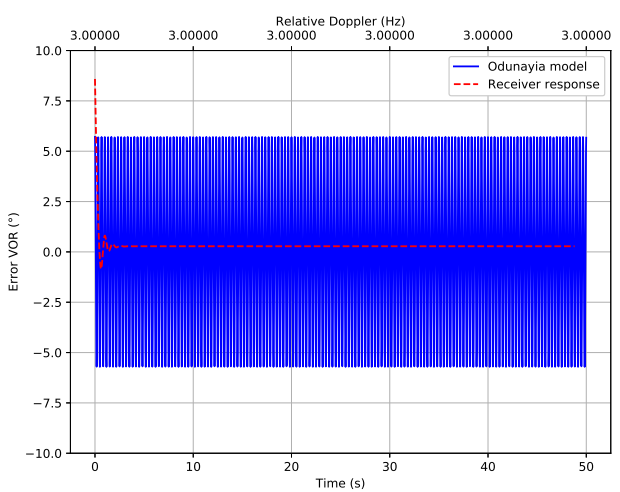

Fig. 11. Receiver response in case 2-b.

some examples for radial and circular aircraft trajectories.

\section{A. Definition}

We consider a general configuration plotted in Figure 12. The aircraft moves in the direction $\hat{\mathbf{u}}_{\mathbf{m}}$.

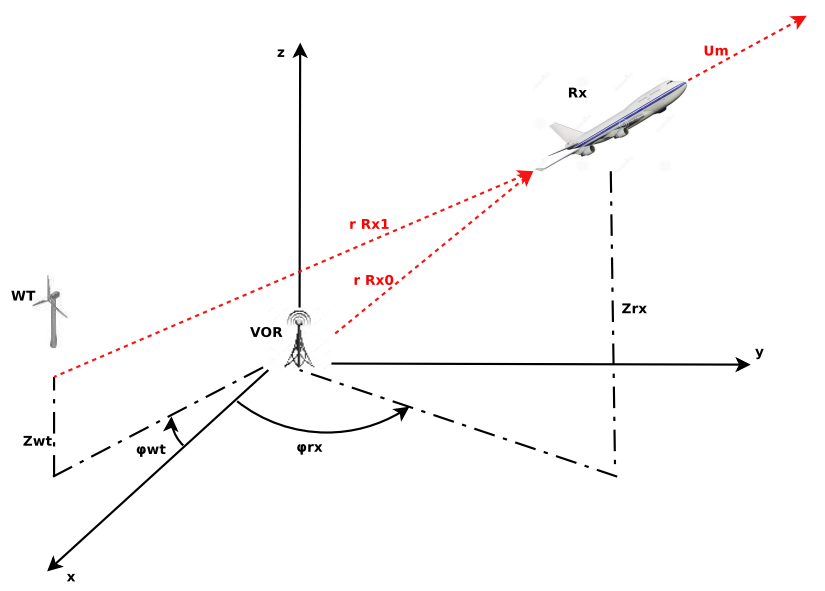

Fig. 12. Configuration.

The aircraft's motion relative to the VOR station yields a Doppler shift given by

$$
\delta f_{D}^{0}=-F_{e} \frac{V_{R x}}{c_{0}} \hat{\mathbf{r}}_{\mathbf{R \mathbf { x } _ { \mathbf { 0 } }}} \cdot \hat{\mathbf{u}}_{\mathbf{m}}
$$

with

- $F_{e}$ the source frequency.

- $V_{R x}$ the receiver speed.

- $c_{0}$ the speed of light.

- $\hat{\mathbf{r}}_{\mathbf{R x}_{\mathbf{0}}}$ the VOR-aircraft direction.

Similarly, the Doppler shift generated by the aircraft's motion relative to the wind turbine is given by

$$
\delta f_{D}^{1}=-F_{e} \frac{V_{R x}}{c_{0}} \hat{\mathbf{r}}_{\mathbf{R x}_{\mathbf{1}}} \cdot \hat{\mathbf{u}}_{\mathbf{m}}
$$

with $\hat{\mathbf{r}}_{\mathbf{R x}_{\mathbf{1}}}$ the wind turbine-aircraft direction. 
If the instantaneous frequency is not included in one of the two filter bandwidths, there is no multipath error. Thus, the Odunaiya model is considered invalid when

$$
\left|\delta f_{D}^{1}-\delta f_{D}^{0}\right|>\frac{\min \left(W_{30}, W_{D C}\right)}{2}
$$

\section{B. Examples}

We consider a VOR station operating at a frequency of $113 \mathrm{MHz}$. An obstacle is placed on azimuth $0^{\circ}$ at $5 \mathrm{~km}$ from the VOR station. The minimum value between the two bandwidths of the receiver filters is set at $10 \mathrm{~Hz}$. We consider a speed of $180 \mathrm{~km} / \mathrm{h}$. The configuration is assumed in a horizontal plane.

In the first case, we consider radial trajectories with distances up to $50 \mathrm{~km}$ from the VOR station. In Figure 13, we observe that the Odunaiya model is invalid in the vicinity of obstacle.

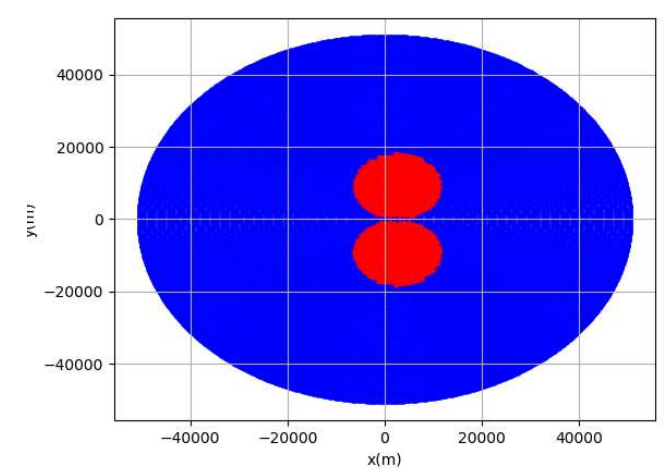

Fig. 13. Validity domain of the Odunaiya expression (in blue).

We consider in the second case a set of circular trajectories around the VOR station. We observe in Figure 14 that the validity area of Odunaiya expression is reduced when compared to radial trajectories.

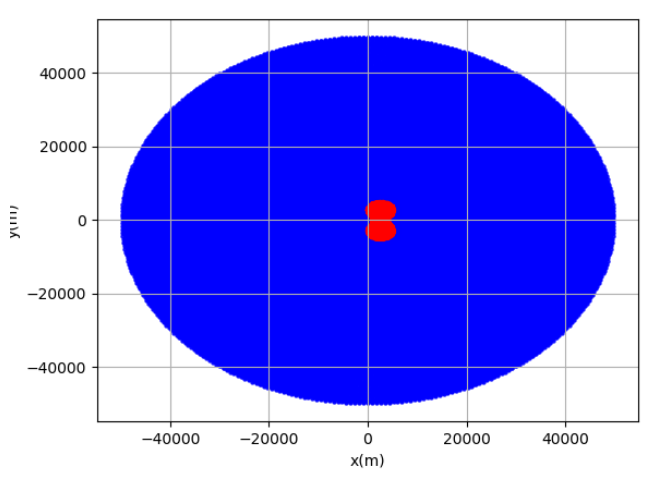

Fig. 14. Validity domain of the Odunaiya expression (in blue).

\section{CONCLUSION}

In this paper, a confrontation between the static Odunaiya expression and the dynamic VOR receiver model has been studied. A spectral analysis of the received intermediate signals in a canonical scenario has been presented to explain the limits of the Odunaiya expression. To obtain the validity domain of this static model, a geometric criterion has been presented and illustrated with some examples. We have observed that the Odunaiya expression is no more valid when the instantaneous frequency of mulitpath due to Doppler effect is filtered inside the digital receiver. Then, the multipaths does not affect the bearing estimation.

\section{ACKNOWLEDGMENT}

The authors would like to thank ENAC and DGAC/DTI for funding this work.

\section{REFERENCES}

[1] S. Odunaiya and D. Quinet, "Calculations and analysis of signal processing by various navigation receivers architectures," in Digital Avionics Systems Conference, vol. 1, 2004.

[2] S. Ben-Hassine, A. Chabory, C. Morlaas, and R. Douvenot, "A Dynamic VOR Receiver Model for Estimating the Bearing Error in the Presence of Wind Turbines," in Proceeding of the 13th European Conference on Antennas and Propagation (EuCAP), April 2019.

[3] L. Claudepierre, R. Douvenot, A. Chabory, and C. Morlaas, "A deterministic VOR error simulation method- Application to windturbines ," IEEE Transactions on Aerospace and Electronic Systems, September 2016.

[4] I. Gonzalez, L. Lozano, J. Gomez, A. Tayebi, I. Etayo, and M. Catedra, "Analysis of the scattering field of wind turbine using rigorous and asymptotic techniques," in Proceeding of the Fourth European Conference on Antennas and Propagation (EuCAP), April 2010, pp. 1-4.

[5] A. Calo Casanova, M. Ramon, L. de Haro y Ariet, and P. BlancoGonzalez, "Wind farming interferences effects," in International MultiConference on Systems, Signals and Devices, July 2008, pp. 1-6. 